DOI: $10.24850 / j-t y c a-2020-05-09$

Notas

\title{
Modelo hidrológico distribuido con imágenes GPM- IMERG en la cuenca del río Huaynamota, Nayarit, México
}

\section{Distributed hydrologic model using GPM-IMERG images in the Huaynamota River Watershed, Nayarit, México}

José Alberto Espinosa-López ${ }^{1}$, ORCID: https://orcid.org/0000-00030392-6004

Laura Alicia Ibáñez-Castillo², ORCID: https://orcid.org/0000-0001-9287$655 X$

Ramón Arteaga-Ramírez³, ORCID: https://orcid.org/0000-0001-94593588

José Mauricio Galeana-Pizaña4, ORCID: https://orcid.org/0000-00033623-6851

1Universidad Autónoma Chapingo, Texcoco, México, alberto.espinosa.74@gmail.com

2Universidad Autónoma Chapingo,Texcoco, México, libacas@gmail.com 3Universidad Autónoma Chapingo, Texcoco, México, arteagar@correo.chapingo.mx 
2020, Instituto Mexicano de Tecnología del Agua

Open Access bajo la licencia CC BY-NC-SA 4.0

(https://creativecommons.org/licenses/by-nc-sa/4.0/)

${ }^{4}$ Centro de Investigación en Geografía y Geomática "Ing. Jorge L. Tamayo", Centro de Investigación en Ciencias de Información Espacial A. C. del Consejo Nacional de Ciencia y Tecnología, Ciudad de México, México,geomauricio23@gmail.com

Autora para correspondencia: Laura Alicia Ibáñez-Castillo, libacas@gmail.com

\section{Resumen}

En México es necesaria la explotación y el control de los recursos hídricos, ya sea para cubrir las diversas carestías o para protegerse del daño causado por eventos extremos. Esta investigación tuvo como objetivo modelar y calibrar los hidrogramas de una cuenca, calculados con datos de lluvia y medidos con imágenes de satélite GPM-IMERG en la cuenca del río Huaynamota, México, así como comparar los resultados con un modelo hidrológico alimentado con datos de lluvia de estaciones meteorológicas automáticas. Esta investigación se realizó en un tributario de la cuenca del río Huaynamota, el cual es parte de la región hidrológica Lerma-Chapala-Santiago. La cuenca se ubica en los estados de Zacatecas, Durango, Jalisco y Nayarit. Para el análisis de los hidrogramas a la salida de la cuenca se evaluaron eventos de lluvia máximos ocurridos en los periodos del 21 al 26 de julio de 2016, del 14 al 24 de agosto de 2017, y del $1^{\circ}$ al 16 de septiembre de 2017 . El modelo se desarrolló en HEC-HMS, con base en métodos como el 
2020, Instituto Mexicano de Tecnología del Agua

Open Access bajo la licencia CC BY-NC-SA 4.0

(https://creativecommons.org/licenses/by-nc-sa/4.0/)

número de curva de escurrimiento y el hidrograma unitario de Clark. La comparación de los hidrogramas medidos y aparentados mostró un buen ajuste de lo simulado con la realidad. En la mayoría de los eventos modelados, el coeficiente de Nash-Sutcliffe fue mayor a 0.5 , que se considera aceptable. Se concluyó que la modelación hidrológica a partir de imágenes de satélites meteorológicos es una buena opción para su implementación en regiones donde se carece de datos de Iluvia horaria medida con instrumentos en tierra.

Palabras clave: imagen de satélite para lluvia GPM-IMERG, hidrograma unitario de Clark, modelo distribuido, modelo agregado.

\section{Abstract}

In Mexico, it is necessary to exploit water resources to cover different needs and to control them to prevent damage caused by extreme events. The objective of this study was to model and calibrate hydrographs calculated with rainfall data measured with GPM-IMERG satellite images in the Huaynamota River Watershed and compare the results with a hydrological model fed rainfall data from automated meteorological stations. The research was conducted in a tributary of the Huaynamota River, which is part of the Lerma-Chapala-Santiago hydrological region. The watershed is located in the states of Zacatecas, Durango, Jalisco and Nayarit. For analysis of the hydrographs at the basin outlet, maximum rainfall events occurring in the periods July 21 to 26, 2016, August 14 to 24, 2017, and September 1 to 16, 2017, were evaluated. The model was developed in HEC-HMS, using methods such 
2020, Instituto Mexicano de Tecnología del Agua

Open Access bajo la licencia CC BY-NC-SA 4.0

(https://creativecommons.org/licenses/by-nc-sa/4.0/)

as the runoff curve number and the Clark unit hydrograph. Comparison of the measured and simulated hydrographs showed good fit of the simulation with reality. In most of the modeled events, the NashSutcliffe coefficient was above 0.5 , which is considered acceptable. We concluded that hydrological modeling using satellite meteorological images is a good option that can be implemented in regions where hourly rainfall data gauged with land instruments are not available.

Keywords: Rainfall GPM-IMERG satellite images, Clark unit hydrograph, distributed model, lumped model.

Recibido: 07/02/2019

Aceptado: 02/12/2019

\section{Introducción}

La comprensión del comportamiento físico de las tormentas es de gran importancia para la solución a diversos problemas asociados con la precipitación, como inundaciones, predicción del clima, agricultura, física de las nubes, etcétera (Ioannidou, Kalogiros, \& Stavrakis, 2016). La 
2020, Instituto Mexicano de Tecnología del Agua

Open Access bajo la licencia CC BY-NC-SA 4.0

(https://creativecommons.org/licenses/by-nc-sa/4.0/)

escasez de datos de Iluvia horaria es un problema que enfrentan los hidrólogos en la modelación de cuencas con fines de pronóstico. La confianza de los resultados de la modelación depende en gran medida de la disponibilidad de la información meteorológica e hidrométrica para calibrar y validar un modelo hidrológico (Magaña-Hernández, Ba, \& Guerra-Cobián, 2013). Además, si los datos requeridos son horarios y se tienen exigencias en cuanto a su distribución espacial, la complejidad de tenerlos crece, porque requiere una capacidad de datos temporal y espacial.

Méndez-Antonio et al. (2013) señalan que tecnologías como el radar y satélites meteorológicos tienen la capacidad para estimar la variabilidad espacial de la precipitación en tiempo real, lo cual es muy útil en modelaciones hidrológicas. Con el apoyo de aplicaciones SIG (Sistema de Información Geográfica) es posible generar información con poca variabilidad temporal al momento del evento.

Con los avances en los sistemas computacionales y el lanzamiento de diferentes misiones espaciales, se ha desarrollado una gran variedad de productos, cuya finalidad es monitorear los cambios físicos en la atmósfera y superficie terrestre; esto ha permitido un desarrollo importante en diferentes áreas de la teledetección (Olivera \& Maidment, 1999).

Los datos de precipitación provenientes de imágenes de satélite están uniformemente distribuidos en el espacio, lo que las convierte en una alternativa para la modelación hidrológica (Zubieta, Getirana, Espinoza, Lavado-Casimiro, \& Aragon, 2017). 
2020, Instituto Mexicano de Tecnología del Agua

Open Access bajo la licencia CC BY-NC-SA 4.0

(https://creativecommons.org/licenses/by-nc-sa/4.0/)

Estos productos reducen las limitaciones en la adquisición y disposición de datos, haciendo posible la implementación de modelos distribuidos, los cuales consideran la variabilidad espacial de las características físicas de la cuenca y la precipitación, dividiendo la cuenca en microcuencas o celdas (Méndez-Antonio, Soto-Cortés, RiveraTrejo, \& Caetano, 2014).

De acuerdo con Méndez-Antonio et al. (2014), una de las ventajas de estos modelos es que permiten el análisis de distintos elementos que influyen en la respuesta hidrológica, como la vegetación y el uso de suelo, generando la posibilidad de obtener los caudales en diferentes puntos de la cuenca; ello es posible pues la variación espacial de la precipitación, infiltración, pérdidas y escurrimiento están explícitamente considerados, mientras que en los modelos agregados, tales variaciones son promediadas o ignoradas.

Algunas desventajas de los modelos agregados, según Vieux (2004), son las siguientes: a) derivar los parámetros a escala de subcuenca es complicado, pues el escurrimiento no está disponible en cada salida; b) la precisión del cálculo de caudales resulta afectada por el número de subcuencas; c) se ignoran o promedian las variaciones de las propiedades en las subcuencas.

El objetivo de este trabajo fue simular los caudales en la cuenca del río Huaynamota, México, mediante el método hidrograma unitario modificado de Clark (ModClark) integrado en HEC-HMS, alimentado con precipitación estimada a partir de imágenes del satélite Global Precipitation Measurement GPM (IMERG), así como calibrar y validar el 
2020, Instituto Mexicano de Tecnología del Agua

Open Access bajo la licencia CC BY-NC-SA 4.0

(https://creativecommons.org/licenses/by-nc-sa/4.0/)

modelo. En la siguiente sección se presentarán explicaciones detalladas de las opciones de cálculo de HEC-HMS.

\section{Materiales y métodos}

\section{Zona de estudio}

La cuenca del río Huaynamota -hasta la estación hidrométrica Chapalagana - forma parte de la Región Hidrológica 12 Lerma-ChapalaSantiago, que abarca parte de los estados de Zacatecas, Durango, Nayarit y Jalisco. Se ubica entre las longitudes oeste $104^{\circ} 35^{\prime}$ y $103^{\circ}$ $20^{\prime}$, y latitud norte $23^{\circ} 25^{\prime}$ y $21^{\circ} 23^{\prime}$. La cuenca cubre una superficie de $12080 \mathrm{~km}^{2}$ hasta la estación de aforo Chapalagana (Figura 1). Este estudio se acota a la cuenca del río Atengo, también conocido como río Chapalagana, un tributario del río Huaynamota; el río Huaynamota tiene dos tributarios principales: los ríos Jesús María y Atengo. Aguas abajo, el río Huaynamota se une al río Santiago, hasta que este último desemboca en el océano Pacífico, en la población Santiago Ixcuintla, 
Tecnología y

Ciencias Agua
2020, Instituto Mexicano de Tecnología del Agua

Open Access bajo la licencia CC BY-NC-SA 4.0

(https://creativecommons.org/licenses/by-nc-sa/4.0/)

Nayarit. La cuenca fue delimitada con HEC-GeoHMS 10.1 (en plataforma ArcMap 10.3), a partir del modelo digital de elevaciones (INEGI, 2017c), con resolución de $15 \mathrm{~m}$; el rango de elevaciones va de 2500 a 220 m. La pendiente media de la cuenca es de $28 \%$; la pendiente del río es de $0.68 \%$; tiene un tiempo de concentración de 38 horas. En promedio, Ilueven anualmente $600 \mathrm{~mm}$, concentrándose la lluvia en los meses de julio a octubre. La cuenca aporta escurrimientos a la presa Aguamilpa, ubicada cerca de $29 \mathrm{~km}$ aguas abajo de la estación de aforo Chapalagana, que es la salida de la cuenca bajo estudio.

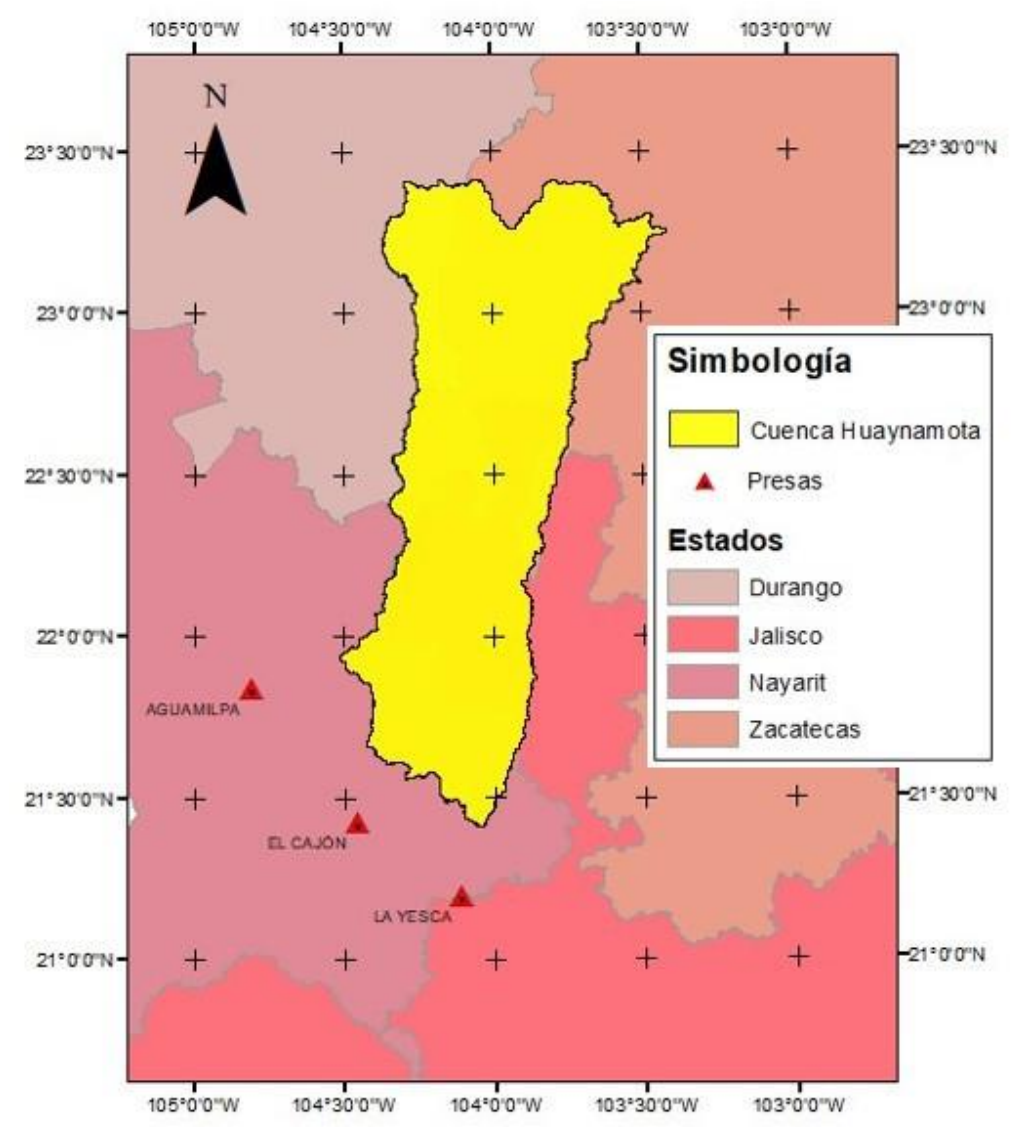


2020, Instituto Mexicano de Tecnología del Agua

Open Access bajo la licencia CC BY-NC-SA 4.0

(https://creativecommons.org/licenses/by-nc-sa/4.0/)

Figura 1. Ubicación de la cuenca del río Huaynamota hasta la estación Chapalagana.

\section{Fuentes de información}

La adquisición de las imágenes GPM (IMERG) GIS está disponible de forma abierta en https://pmm.nasa.gov/data-access/downloads/gpm; estas imágenes tienen una resolución espacial de $0.1^{\circ} \times 0.1^{\circ}$, con una temporalidad de 30 minutos (Huffman et al., 2017).

Los datos hidrométricos de la estación Chapalagana y de precipitación de las EMAS (Tabla 1), ambos datos horarios, fueron obtenidos por la Comisión Federal de Electricidad (CFE, 2018).

Tabla 1. Estaciones meteorológicas automáticas en la cuenca del río Huaynamota hasta la estación Chapalagana.

\begin{tabular}{llcl}
\hline \multicolumn{1}{c}{ Administrador } & \multicolumn{1}{c}{ Nombre } & Longitud & Latitud \\
\hline CFE & Florida & $-103.6036^{\circ}$ & $22.6864^{\circ}$ \\
CFE & Platanitos & $-104.063^{\circ}$ & $22.5680^{\circ}$ \\
CFE & Bolaños & $-103.7833^{\circ}$ & $21.8250^{\circ}$
\end{tabular}


Tecnología y

Ciencias $₫$ Agua
2020, Instituto Mexicano de Tecnología del Agua

Open Access bajo la licencia CC BY-NC-SA 4.0

(https://creativecommons.org/licenses/by-nc-sa/4.0/)

CFE

Jesús María

$-104.5160^{\circ} \quad 22.2550^{\circ}$

CFE

Chapalagana

$-104.5080^{\circ} \quad 21.9450^{\circ}$

Para la construcción del mapa digital ráster, que muestra la variación espacial del número de curva de escurrimiento (CN), se utilizó el conjunto de datos vectoriales de uso de suelo y vegetación del Instituto Nacional de Estadística y Geografía (INEGI), escala 1:250 000 serie V, 2011-2012 (INEGI, 2017a), y del conjunto de datos vectorial edafológico escala 1:250,000 serie II, 2002-2007 (INEGI, 2017b).

\section{Procedimiento}

La función de producción de escurrimiento, derivada del método de número de curva de escurrimiento (CN) del Servicio de Conservación de Suelos, desarrollado por el Departamento de Agricultura de Estados Unidos, es uno de los métodos más utilizados debido a su sencillez para la estimación de la precipitación en exceso como una función de la precipitación acumulada, tipo de suelo, vegetación y humedad antecedente (Ponce \& Hawkins, 1996). 
2020, Instituto Mexicano de Tecnología del Agua

Open Access bajo la licencia CC BY-NC-SA 4.0 (https://creativecommons.org/licenses/by-nc-sa/4.0/)

El procedimiento se basa en la ecuación de balance hídrico y en dos hipótesis fundamentales de acuerdo con Sithara (2015). La primera establece que la relación entre el volumen de escurrimiento directo y el escurrimiento potencial máximo correspondiente a una superficie impermeable es igual a la relación entre la infiltración real y la infiltración potencial máxima. La segunda hipótesis establece que la infiltración inicial es una fracción de la retención potencial. La Ecuación (1), Ecuación (2) y Ecuación (3) representan las hipótesis mencionadas anteriormente:

$P=I_{a}+F+Q$

$\frac{Q}{P-I_{a}}=\frac{F}{S}$

$I_{a}=\lambda S$

Donde $Q=$ escurrimiento directo o precipitación efectiva $(\mathrm{mm}) ; P$ $=$ precipitación total $(\mathrm{mm}) ; I_{a}=$ abstracciones iniciales $(\mathrm{mm}) ; F=$ infiltración acumulada excluyendo $I_{a} ; S=$ retención o infiltración potencial máxima $(\mathrm{mm})$. Para aplicaciones prácticas, se supone $I_{a}=0.2$ $S$. 
2020, Instituto Mexicano de Tecnología del Agua

Open Access bajo la licencia CC BY-NC-SA 4.0 (https://creativecommons.org/licenses/by-nc-sa/4.0/)

Como abstracciones iniciales se consideran cinco categorías según Ponce y Hawkins (1996): (1) intercepción por el follaje de la vegetación; (2) intercepción en embalses; (3) infiltración al subsuelo; evaporación de cuerpos de agua y del mismo suelo, y evapotranspiración de la vegetación.

Combinando la Ecuación (1) y la Ecuación (2) se tiene:

$Q=\frac{\left(P-I_{a}\right)^{2}}{\left(P-I_{a}+S\right)}$

Sustituyendo $I_{a}=0.2 \mathrm{~S}$ en la Ecuación (4):

$$
Q=\frac{(P-0.2 S)^{2}}{(P+0.8 S)}
$$

Donde $Q=0$ para $P \leq 0.2 S ; S$, en términos de $C N$, se representa con la Ecuación (6):

$$
S=\frac{25400}{C N}-254
$$

Donde $C N=$ número de curva de escurrimiento. Para darse una idea del rango de variación de los valores de $C N$; un $C N=98$ representa 
2020, Instituto Mexicano de Tecnología del Agua

Open Access bajo la licencia CC BY-NC-SA 4.0

(https://creativecommons.org/licenses/by-nc-sa/4.0/)

una superficie impermeable, y un $C N=30$ es para suelos permeables y altas tasas de infiltración (USACE, 2000).

La función de transferencia del escurrimiento se realiza con el método del hidrograma unitario modificado de Clark. De acuerdo con Kull y Feldman (1998), el método consiste en transitar el escurrimiento producido en cada celda hasta la salida de la cuenca después de transcurrir un intervalo de tiempo igual al recorrido desde la celda hasta la salida (Ecuación (7)):

$t_{\text {celda }}=t c\left(\frac{d_{\text {celda }}}{d_{\text {máx }}}\right)$

Donde $t_{c e l d a}$ es el tiempo de viaje de la celda en horas; $t_{c}$, el tiempo de concentración de la cuenca en horas; $d_{c e l d a}$, la distancia de viaje de una celda hasta la salida de la cuenca en metros, y $d_{\text {máx }}$ es la distancia de viaje para la celda que está más distante de la salida. Los resultados de cada celda se combinan para producir el hidrograma final, como se muestra conceptualmente en la Figura 2. 
Tecnología y

Ciencias $₫$ Agua
2020, Instituto Mexicano de Tecnología del Agua

Open Access bajo la licencia CC BY-NC-SA 4.0 (https://creativecommons.org/licenses/by-nc-sa/4.0/)

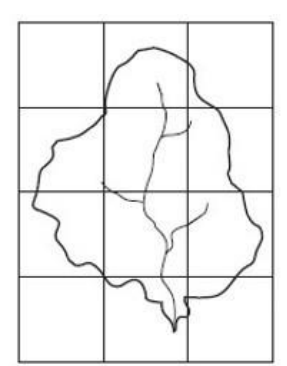

Malla superpuesta en la cuenca

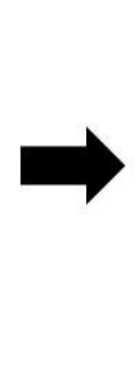

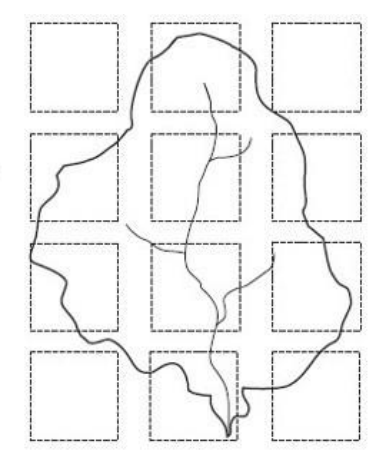

Descarga de celdas: función del área de celda, lluvia, infiltración y tiempo de viaje
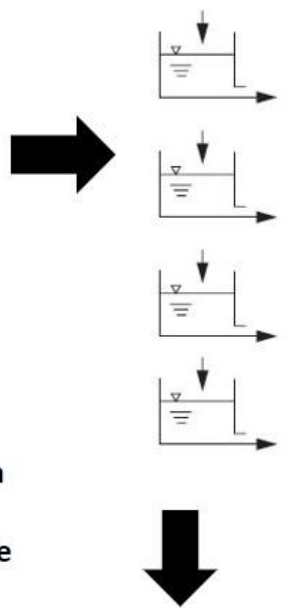
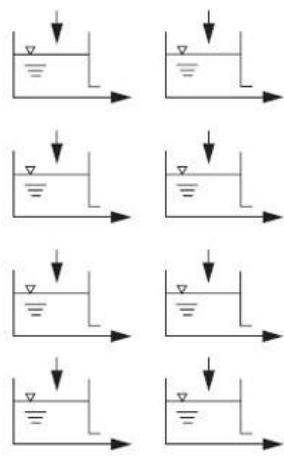

Atenuación por almacenamiento

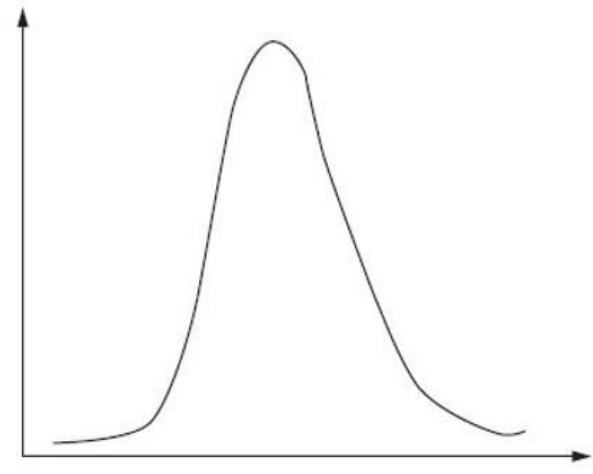

Hidrograma de escurrimiento directo de la cuenca
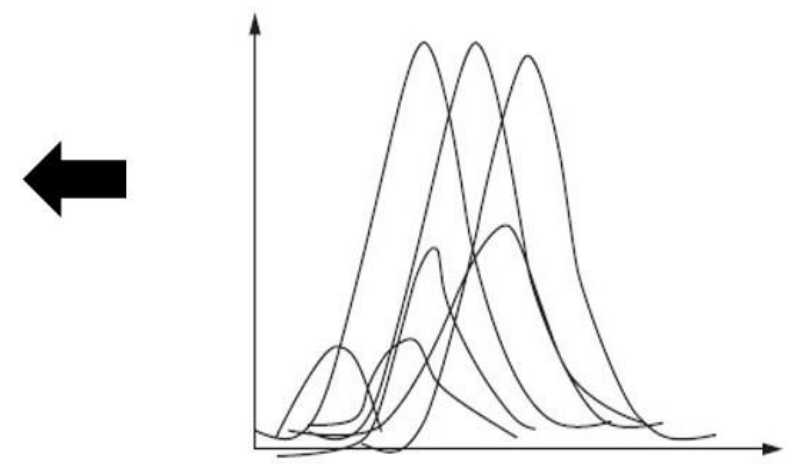

Hidrograma de salida de cada celda

Figura 2. Modelo conceptual hidrograma unitario modificado de Clark (Kull \& Feldman, 1998).

Para el cálculo del hidrograma producido en la cuenca, el método ModClark requiere la estimación de los parámetros tiempo de concentración $\left(t_{c}\right)$ y coeficiente de almacenamiento $(R)$.

Según McCuen, Wong y Rawls (1984), existen dos definiciones aceptadas para el tiempo de concentración $\left(t_{c}\right)$. En la primera, $t_{c}$ está definido como el tiempo que requiere una gota de agua en llegar del 
2020, Instituto Mexicano de Tecnología del Agua

Open Access bajo la licencia CC BY-NC-SA 4.0

(https://creativecommons.org/licenses/by-nc-sa/4.0/)

punto más alejado de la cuenca hasta la salida de ésta. En la segunda, el $t_{c}$ se basa en el hietograma de la tormenta y el hidrograma; el tiempo de concentración es el tiempo entre el centro de masa de la lluvia en exceso y el punto de inflexión en la recesión del hidrograma del escurrimiento directo. En la investigación se usó la ecuación de Kirpich expresada en la Ecuación (8) (Chow, Maidment, \& Mays, 1988):

$t_{c}=0.000325 \frac{L^{0.77}}{S^{0.385}}$

Donde $t_{c}$ es el tiempo de concentración en $h$; $L$, la longitud del cauce principal de la cuenca en $m$, y $S$ es la pendiente del cauce principal $(\mathrm{m} / \mathrm{m})$.

El coeficiente de almacenamiento se estima desde un hidrograma observado. Representa la razón entre el volumen bajo del hidrograma después del segundo punto de inflexión (curva de recesión) y el valor del gasto en este punto USACE, (1982). La Ecuación (9) estima tal coeficiente:

$R=\frac{\int_{P I}^{\infty} Q(t)}{Q_{P I}} d t$ 
2020, Instituto Mexicano de Tecnología del Agua

Open Access bajo la licencia CC BY-NC-SA 4.0

(https://creativecommons.org/licenses/by-nc-sa/4.0/)

Donde $R$ es el coeficiente de almacenamiento; $\int_{P I}^{\infty} Q(t)$, el volumen bajo el hidrograma después del segundo punto de inflexión, y $Q_{P I}$ es el valor en el punto de inflexión.

La literatura indica que el coeficiente de almacenamiento $R$ es $C$ veces el tiempo de concentración, como se indica en la Ecuación (10):

$R=c \times t_{c}$

Domínguez et al. (2008) indican que $c$ puede ser igual a 0.6; la US Army Corps of Engineers, citada por Magaña-Hernández et al. (2013), recomienda que $c$ sea igual a 0.8 . En este trabajo se calculó con $0.75 \cdot t_{c}$, pues generó mejores resultados en el proceso de calibración.

El tránsito de los escurrimientos se hizo con el método Muskingum, con la siguiente ecuación:

$S=K[x I]+(1-x) O$

La Ecuación (11) es una relación entre el almacenamiento (S), las entradas $(I)$ y las salidas $(O)$ del tramo en análisis (Bedient, Huber, \& Vieux, 2013), donde $S$ es el almacenamiento en el tramo de corriente; $I$, el caudal de entrada; $O$, el caudal de salida; $K$, la constante de tiempo de recorrido del tramo de corriente; $y x$ es un factor de peso que 
2020, Instituto Mexicano de Tecnología del Agua

Open Access bajo la licencia CC BY-NC-SA 4.0

(https://creativecommons.org/licenses/by-nc-sa/4.0/)

relaciona las entradas y salidas del almacenamiento en el tramo de corriente.

Para la evaluación del modelo se usaron dos medidores: el coeficiente eficiencia de Nash-Sutcliffe (NSE) (Nash \& Sutcliffe, 1970) y la raíz del cuadrado medio del error (RSME) (Vargas-Castañeda, IbáñezCastillo, \& Arteaga-Ramírez, 2015):

$N S E=1-\left[\frac{\sum_{i=1}^{n}\left(Y_{i}^{o b s}-Y_{i}^{s i m}\right)^{2}}{\sum_{i=1}^{n}\left(Y_{i}^{\text {obs }}-Y^{m e d}\right)^{2}}\right]$

$R S M E=\sqrt{\frac{1}{n} \sum_{i=1}^{n}\left(Y_{i}^{o b s}-Y_{i}^{s i m}\right)^{2}}$

Donde $Y^{o b s}$ es el valor observado; $Y$ sim, el dato simulado, y $Y^{\text {media }}$ es la media de los datos observados.

El coeficiente de NSE evalúa la magnitud de la varianza residual entre los datos observados y modelados (Ecuación (12)). El coeficiente varía de $-\infty$ a 1 ; si $\mathrm{NSE}=1$, el valor es óptimo; entre 0 y 1 es aceptable; para valores $\leq 0$ se considera a la media como mejor predictor que el valor simulado, considerando inaceptable el desempeño del modelo. Moriasi et al. (2007) proponen los rangos en NSE en la Tabla 2. 
2020, Instituto Mexicano de Tecnología del Agua

Open Access bajo la licencia CC BY-NC-SA 4.0

(https://creativecommons.org/licenses/by-nc-sa/4.0/)

Tabla 2. Criterios de evaluación de los modelos hidrológicos empleando el índice de eficiencia de Nash-Sutcliffe (NSE).

\begin{tabular}{cc}
\hline Intervalo & Clasificación \\
\hline NSE $<0.5$ & Insatisfactorio \\
$0.5<$ NSE $<0.65$ & Satisfactorio \\
$0.65<$ NSE $<0.75$ & Bueno \\
$0.75<$ NSE $<1.0$ & Muy bueno \\
\hline
\end{tabular}

El coeficiente RSME (Ecuación (13)) mide el error medio en términos absolutos entre lo observado y simulado, y tiene las unidades de los caudales de los hidrogramas que se comparan, en este caso $\mathrm{m}^{3} / \mathrm{s}$.

Para la implementación del modelo fue necesario lo siguiente:

Se determinaron las características fisiográficas (Figura 3) a partir de un modelo digital de elevación (MDE) descargado del continuo de elevaciones mexicano 3.0 (CEM 3.0), que está a una resolución de 15 m; los productos fueron la delimitación de la cuenca y subcuencas, identificación del cauce principal y los parámetros fisiográficos mediante la extensión HEC-GeoHMS, distribuida de forma gratuita por USACE (2013) para ArcMap 10.3. 
2020, Instituto Mexicano de Tecnología del Agua

Open Access bajo la licencia CC BY-NC-SA 4.0

(https://creativecommons.org/licenses/by-nc-sa/4.0/)

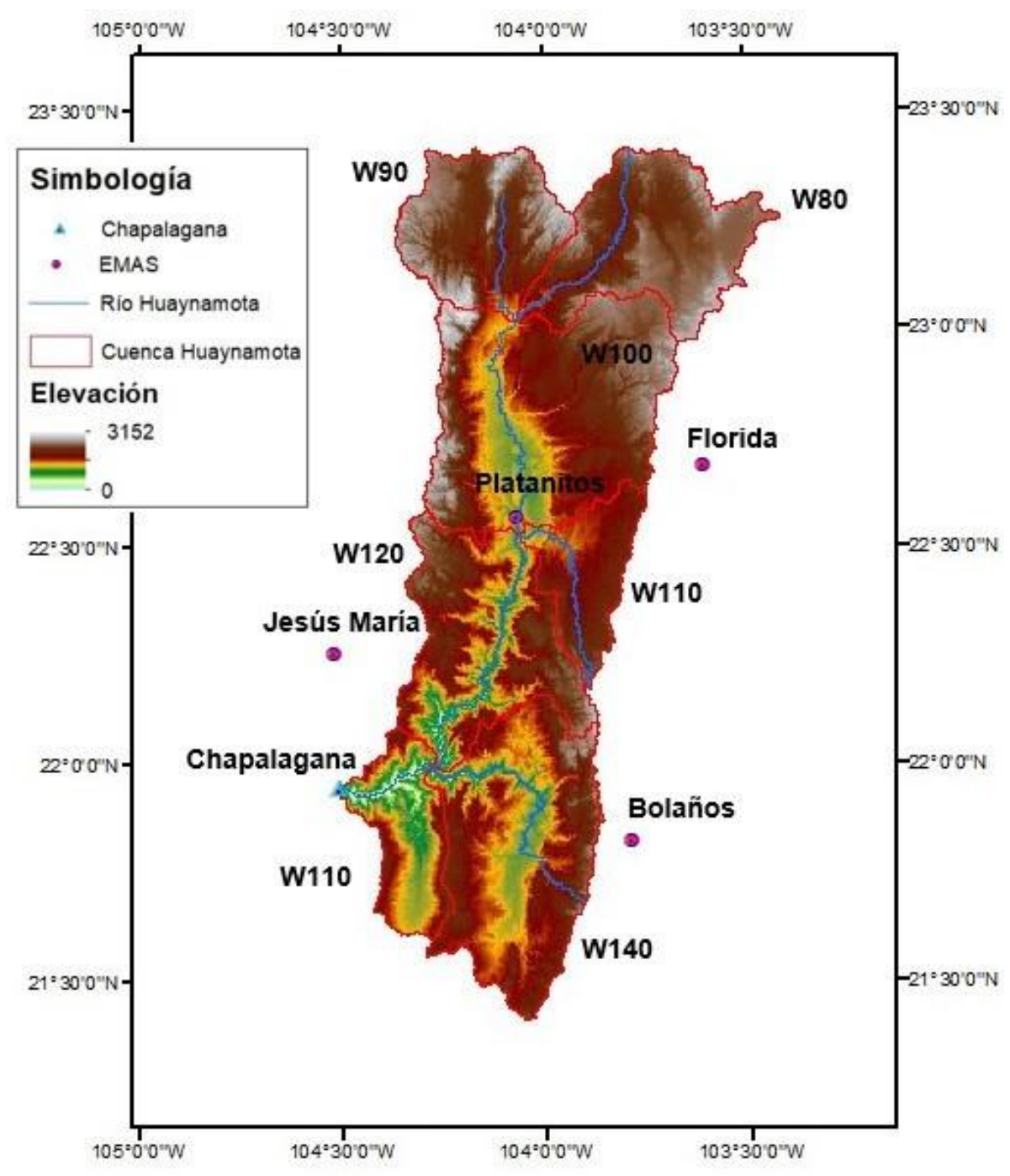

Figura 3. Subcuencas del río Huaynamota hasta la estación

Chapalagana en Nayarit.

La variación espacial del número de curva de escurrimiento CN (Figura 4), se determinó con las capas vectoriales de edafología serie II, y uso de suelo y vegetación serie V del INEGI (2017a), con el 
Tecnología y

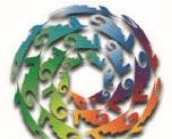

Ciencias $\stackrel{\unlhd}{\unlhd}$ gua
2020, Instituto Mexicano de Tecnología del Agua

Open Access bajo la licencia CC BY-NC-SA 4.0

(https://creativecommons.org/licenses/by-nc-sa/4.0/)

procedimiento propuesto por USACE (2013) en HEC-GeoHMS para ArcMap 10.3.
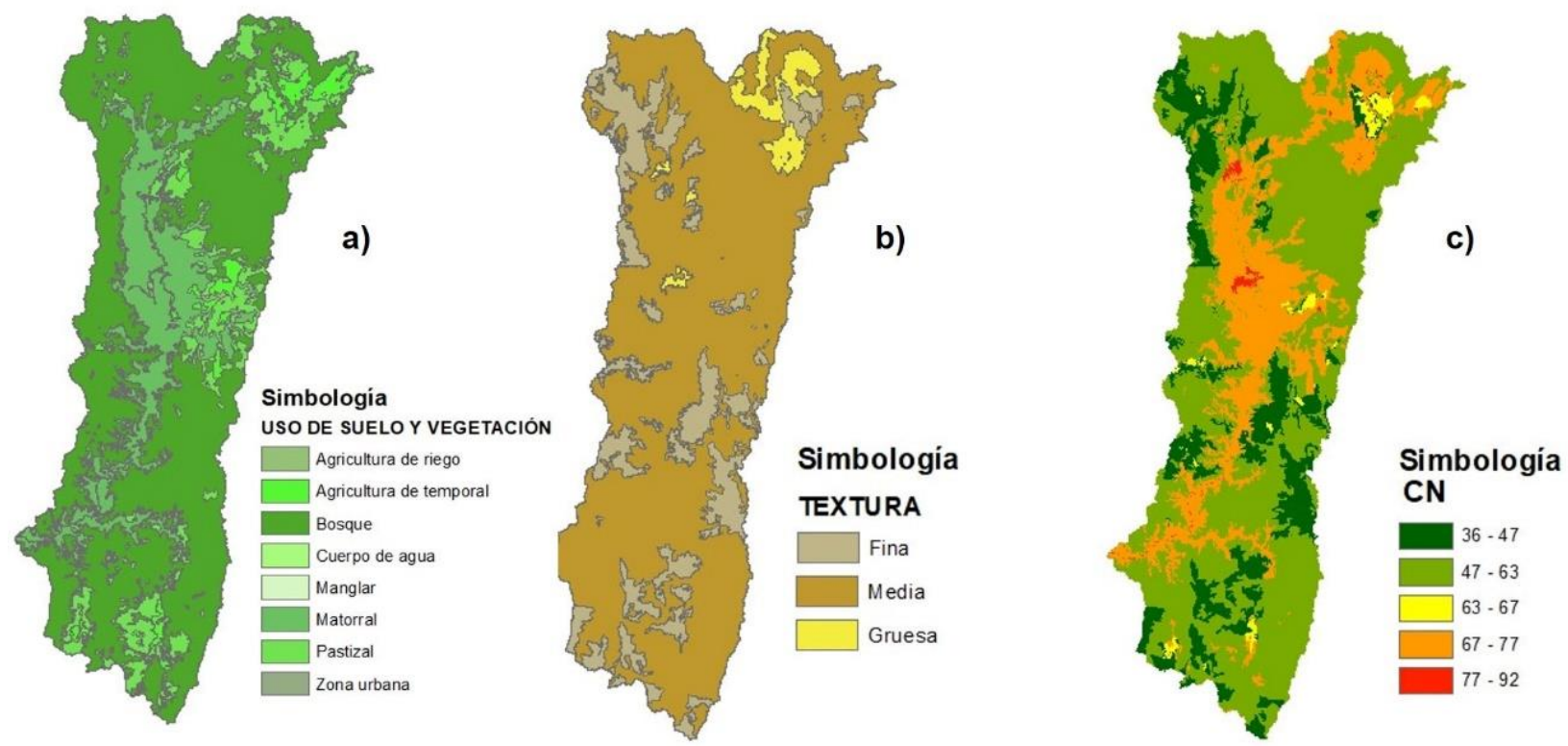

Figura 4. a) Uso de suelo y vegetación; b) tipo de textura; c) número de curva en la cuenca del río Huaynamota.

\section{El proceso de calibración del modelo hidrológico en HEC- HMS versión 4.2}


2020, Instituto Mexicano de Tecnología del Agua

Open Access bajo la licencia CC BY-NC-SA 4.0

(https://creativecommons.org/licenses/by-nc-sa/4.0/)

Los caudales observados pueden utilizarse para optimizar el funcionamiento del modelo por medio de la estimación o mejora de los valores de los parámetros. El proceso de optimización empieza con valores iniciales de los parámetros y éstos se ajustan para que los resultados simulados se aproximen a los caudales observados y sea lo más certero posible. HEC-HMS versión 4.2 usa dos algoritmos de búsqueda de los parámetros que minimizan esa diferencia o error; tales algoritmos parten del valor inicial que se les da hasta encontrar el valor óptimo. El objetivo de ese algoritmo de búsqueda es minimizar la diferencia entre valores observados y simulados. Si los hidrogramas observados y simulados fueron totalmente idénticos, ese error o diferencia sería cero.

Algoritmo de búsqueda: los dos algoritmos de búsqueda que puede usar el HEC-HMS versión 4.2 son el método del gradiente univariado, y de Nelder y Mead (USACE, 2015). El gradiente univariado evalúa y ajusta un parámetro, mientras que el resto los deja constantes. El método de Nelder y Mead usa un algoritmo símplex, para evaluar todos los parámetros de manera simultánea y determina qué parámetro ajustar. HEC-HMS usa por default el método del gradiente univariado.

Función objetivo: la función objetivo mide la bondad de ajuste entre los caudales calculados y observados. HEC-HMS 4.2 da la opción de entre ocho funciones objetivos diferentes (USACE, 2015): (1) función de error RMSE, que calcula la raíz del cuadrado medio del error; (2) función de error RMSE ponderada, que es parecida a la función objetivo anterior, con la diferencia de que le da más peso a los caudales que 
2020, Instituto Mexicano de Tecnología del Agua

Open Access bajo la licencia CC BY-NC-SA 4.0

(https://creativecommons.org/licenses/by-nc-sa/4.0/)

están por arriba de la media y menos peso a los caudales debajo de la media; el manual de usuario HEC-HMS no da detalles de qué tanto es ese peso ponderado; (3) función de error RMSE aplicado a los logaritmos de caudales para hacer énfasis en las diferencias de caudales pequeños y grandes; (4) la función suma del cuadrado de los residuales SSR da mayor peso a errores grandes que pequeños; (5) la función suma de los residuales absolutos da peso igual a los errores grandes y pequeños; (6) la función de porcentaje de error en el caudal máximo sólo da énfasis a ese valor; (7) la función de error del volumen ignora caudales máximos o consideraciones del momento real en que ocurren los caudales, en favor de sólo considerar optimizar volumen; (8) la función tiempo de ocurrencia da mayor énfasis a los errores que ocurren al final y menos a los que ocurren al principio, lo cual favorece una etapa de "calentamiento" del modelo. El HEC-HMS, por default elige la función \#2, aquella que da mayor importancia a no equivocarse al momento de calcular los caudales que están por arriba de la media.

Calibración de este modelo: este trabajo se realizó en HECHMS versión 4.2; se usó como algoritmo de búsqueda del valor óptimo el método del gradiente univariado y la función objetivo que se consideró fue la que da mayor penalización al equivocarse en calcular un caudal por arriba de la media. Esta última elección fue porque se espera que el modelo sea útil para pronóstico de avenidas, a fin de alertar a poblaciones, y dicha alerta es mayor con caudales arriba de la media. El modelo HEC-HMS informó como coeficientes de ajuste a la raíz del cuadrado medio del error (RSME) y el coeficiente de Nash-Sutcliffe. 
2020, Instituto Mexicano de Tecnología del Agua

Open Access bajo la licencia CC BY-NC-SA 4.0

(https://creativecommons.org/licenses/by-nc-sa/4.0/)

(NS). El usuario tiene la opción de generar de manera automática y otorgarle al HMS un grupo de parámetros a optimizar; por ejemplo, primero todos los números de curva de escurrimiento por subcuenca; los tiempos de retraso; los tiempos de concentración, o todos los parámetros de tránsito en cauces, etcétera. Incluso por prueba y error, adicionar un parámetro y ver qué tan sensible es la función objetivo a tales cambios. En este trabajo se hicieron varias pruebas (por prueba y error), sumando parámetros y observando cuán sensible se comportaba el proceso de optimización, ya que HEC-HMS, para cada parámetro optimizado, reporta lo que se llama objective function sensitivity. La literatura informa que de los modelos hidrológicos superficiales, uno de los parámetros más sensibles es el número de curva de escurrimiento (Moriasi et al., 2007), cuestión que se pudo comprobar; sin embargo, se partió de un valor de NC, obtenido a partir del tipo de suelo y cobertura vegetal, y sólo se permitió que dicho parámetro variara hasta $\pm 20 \%$ al momento de calibrar. El otro parámetro que se determinó con sensibilidad fue al coeficiente de almacenamiento $R$ (Ecuación (10)), el cual es $c$ veces el tiempo de concentración. Se probaron valores entre 0.6 y 0.75 , tal como lo reporta la literatura (Domínguez et al., 2008; Magaña-Hernández et al., 2013), y se obtuvo mejor respuesta a que el valor de $c$ fuera de 0.75 . Se probaron los parámetros de tránsito de avenida en cauces con Muskingum, $K$ y $x$, pero no hubo mejora notable en la disminución del error entre los caudales observados y simulados. No se deseó elegir el modo automático de calibración HEC-HMS, porque 
2020, Instituto Mexicano de Tecnología del Agua

Open Access bajo la licencia CC BY-NC-SA 4.0

(https://creativecommons.org/licenses/by-nc-sa/4.0/)

modifica notablemente los parámetros hidrológicos de manera arbitraria con tal de forzar el ajuste entre lo observado y simulado.

En resumen, se exponen tres comentarios finales acerca del procedimiento:

- Se corrieron dos modelos hidrológicos en el ambiente del software HEC-HMS versión 4.2: (1) un modelo hidrológico agregado con HU de Clark original, con información meteorológica horaria proveniente de las EMA de CFE; (2) un modelo hidrológico distribuido con el HU de Clark modificado, con la información meteorológica horaria derivada de las imágenes de satélite GPMIMERG. Ambos modelos usaron la metodología de número de curva de escurrimiento para calcular láminas escurridas; ambos modelos hicieron el tránsito de avenidas en cauces con el método de Muskingum.

- En la construcción de la base de datos de lluvia, provenientes de imágenes de satélite, se generaron series de tiempo con las imágenes GPM-IMERG para cada evento seleccionado. El preproceso de las imágenes se realizó en ArcMap, para después convertirlas al formato *.dss, con la herramienta asc2dssGrid.exe (USACE, 2016), incluido en la extensión HECGeoHMS.

- Los eventos de lluvia considerados en la modelación fueron tres: (1) del 21 al 26 de julio de 2016; (2) del 14 al 24 de agosto de 2017; (3) del 1 al 16 de septiembre de 2017. En estas fechas se tuvieron disponibles los datos de imágenes de satélite de Iluvia 
GPM-IMERG y los datos horarios de lluvia y caudal de las EMA de la Comisión Federal de Electricidad.

\section{Resultados}

La Tabla 3 muestran los resultados de los modelos hidrológicos ejecutados tanto con la información de EMA de CFE como la corrida con datos de lluvia de las imágenes de satélite. Además, se observa que Ios mejores resultados se consiguen a partir de aquellos modelos hidrológicos alimentados de forma directa con la lluvia registrada por las EMA de la CFE. Los modelos hidrológicos alimentados con datos de lluvia estimados de imágenes de satélite presentan menor ajuste, medido tanto con índice de eficiencia de Nash, NSE, como con la raíz del cuadrado medio del error (RSME). Es probable que los datos de imágenes no hayan sido calibrados por la NASA con información tan detallada, en forma temporal y espacial, como lo es la de la CFE; pero cabe recordar que la CFE, a diferencia del Servicio Meteorológico Nacional, no tiene abiertos sus datos al público. Sin embargo, hay lugares de México donde no hay datos de EMA de CFE o del SMN distribuidos espacialmente de la manera deseada o ni siquiera existen . 
2020, Instituto Mexicano de Tecnología del Agua

Open Access bajo la licencia CC BY-NC-SA 4.0 (https://creativecommons.org/licenses/by-nc-sa/4.0/)

Las imágenes de la NASA son una alternativa para desarrollar modelos hidrológicos. Además de los tres eventos modelados en este trabajo, sólo el del 21 al 26 de julio del 2016 presentó un ajuste pobre, medido con el índice de eficiencia de Nash, NSE y también medido con RSME.

Tabla 3. Resultados de los modelos hidrológicos calibrados.

\begin{tabular}{lccccccc}
\hline $\begin{array}{l}\text { Fecha del } \\
\text { evento }\end{array}$ & $\begin{array}{c}\text { Fuente } \\
\text { datos } \\
\text { lluvia }\end{array}$ & $\begin{array}{c}\text { Qcalc } \\
\left(\mathrm{m}^{3} \mathbf{s}^{-1}\right)\end{array}$ & $\begin{array}{c}\text { Qobs } \\
\left(\mathrm{m}^{3} \mathbf{s}^{-1}\right)\end{array}$ & $\begin{array}{c}\text { Vcalc } \\
(\mathbf{m m})\end{array}$ & $\begin{array}{c}\text { Vobs } \\
(\mathbf{m m})\end{array}$ & $\begin{array}{c}\text { RSME } \\
\left(\mathrm{m}^{3} \mathbf{s}^{-1}\right)\end{array}$ & NSE \\
& & & & & & & \\
\end{tabular}

Del 21 al

EMA

440.2

641.9

4.52

3.73

$73.0 \quad 0.625$

26 de julio

de 2016

\begin{tabular}{|c|c|c|c|c|c|c|c|}
\hline & $\begin{array}{c}\text { Imágenes } \\
\text { de } \\
\text { satélite }\end{array}$ & 373.6 & 641.9 & 3.33 & 3.73 & 129.3 & -0.159 \\
\hline \multirow[t]{2}{*}{$\begin{array}{l}\text { Del } 14 \text { al } \\
24 \text { de } \\
\text { agosto de } \\
2017\end{array}$} & EMA & 439.5 & 465.9 & 5.06 & 5.18 & 23.0 & 0.932 \\
\hline & $\begin{array}{c}\text { Imágenes } \\
\text { de } \\
\text { satélite }\end{array}$ & 462.0 & 465.9 & 6.26 & 5.18 & 60.5 & 0.531 \\
\hline $\begin{array}{l}\text { Del } 1^{\circ} \text { al } \\
16 \text { de } \\
\text { septiembre } \\
\text { de } 2017\end{array}$ & EMA & 624.7 & 1171.0 & 32.44 & 35.22 & 186.7 & 0.567 \\
\hline
\end{tabular}


Tecnología y

Ciencias $₫$ Agua
2020, Instituto Mexicano de Tecnología del Agua

Open Access bajo la licencia CC BY-NC-SA 4.0 (https://creativecommons.org/licenses/by-nc-sa/4.0/)

$\begin{array}{lccccccc}\text { Evento } & \text { Imágenes } & 969.4 & 1171.0 & 44.16 & 35.22 & 194.3 & 0.530 \\ \text { máximo } & \text { de } & & & & & & \\ \text { del año } & \text { satélite } & & & & & & \\ 2017 & & & & & & & \end{array}$

La Figura 5 expone los datos procesados de lluvia a partir de las imágenes de satélite para el evento del 21 al 26 de julio de 2016; la Figura 6 muestra las corridas del modelo tanto con datos de EMA como con datos de imágenes de satélite. Se observa, en lo que respecta a caudales máximos, que el modelo alimentado con datos de EMA presenta mejores resultados tanto para predecir valor como la hora en que ocurrió. 


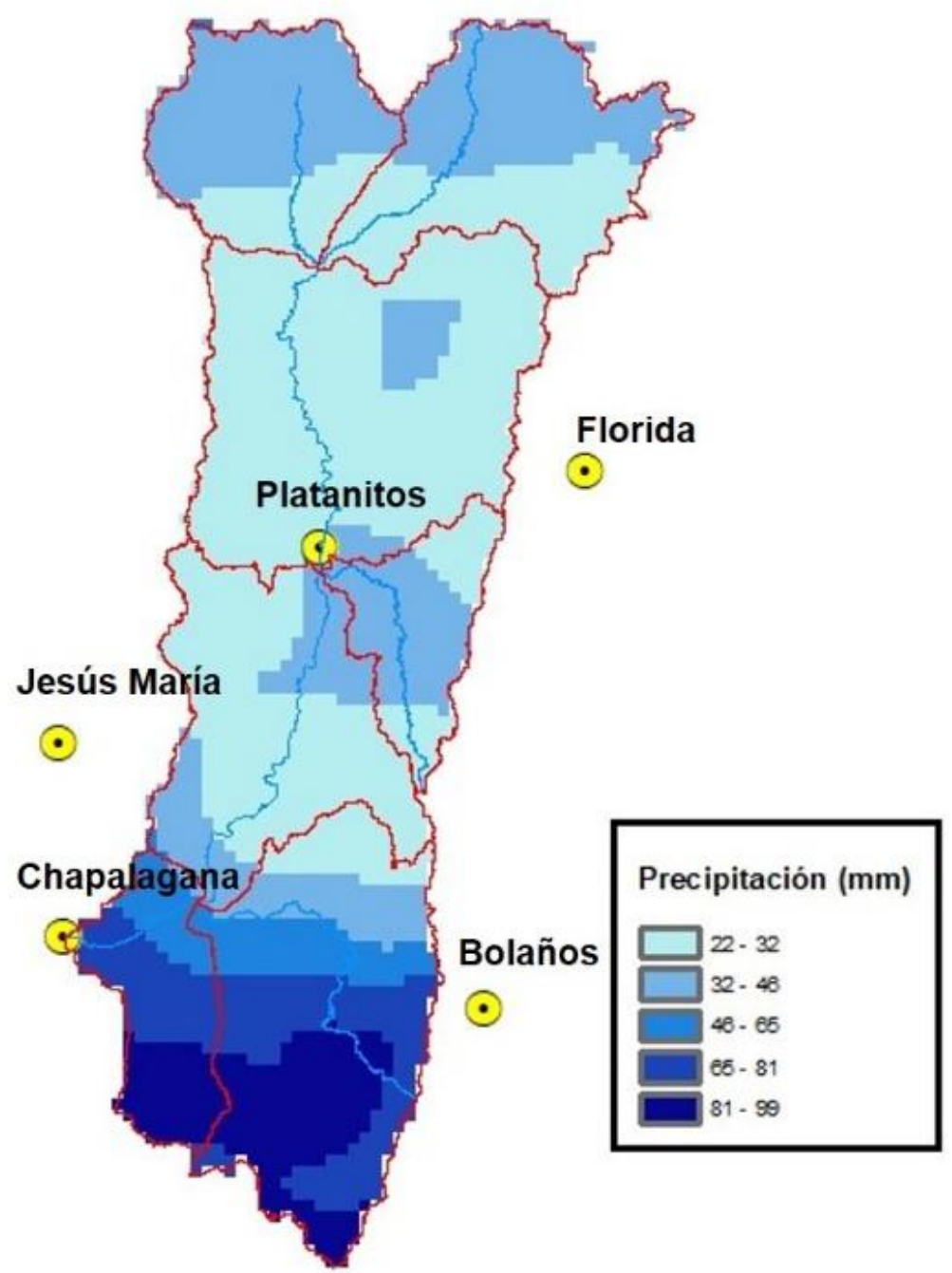

Figura 5. Precipitación acumulada con imágenes GPM-IMERG para el evento del 21 al 26 de julio 2016. 
Tecnología y

Ciencias $₫$ Agua
2020, Instituto Mexicano de Tecnología del Agua

Open Access bajo la licencia CC BY-NC-SA 4.0

(https://creativecommons.org/licenses/by-nc-sa/4.0/)

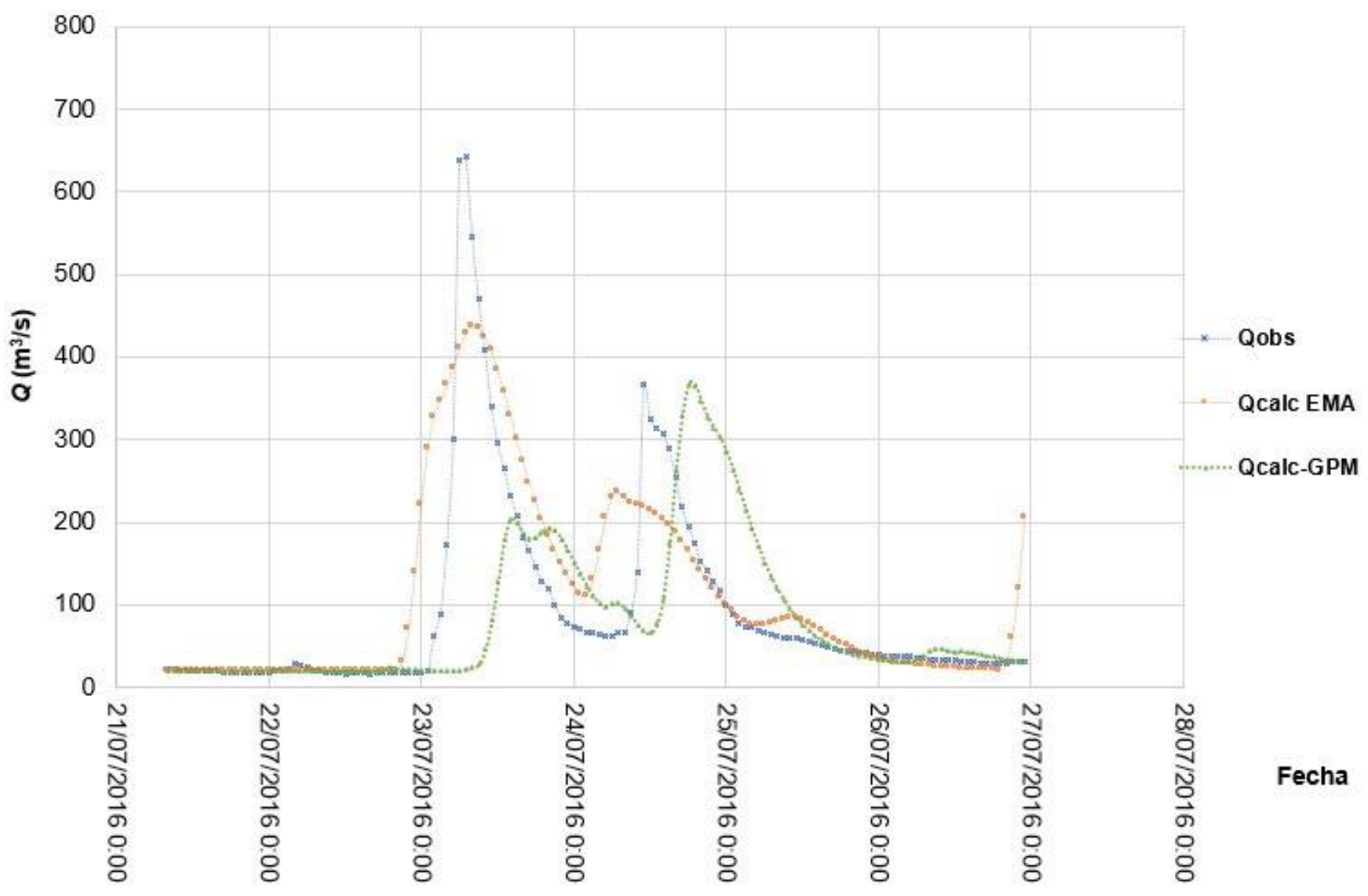

Figura 6. Caudales observados y simulados en la estación Chapalagana para los eventos ocurridos del 21 al 26 de julio de 2016.

La Figura 7 muestra los datos procesados de lluvia a partir de las imágenes de satélite para el evento del 14 al 24 de agosto de 2017; la Figura 8 expresa las corridas del modelo tanto con datos de EMA como con imágenes de satélite. Se observa, en lo que respecta a caudales máximos, que el modelo alimentado con datos de EMA presenta los mejores resultados (NSE $=0.932$ ); casi se sobreponen las gráficas de 
2020, Instituto Mexicano de Tecnología del Agua

Open Access bajo la licencia CC BY-NC-SA 4.0

(https://creativecommons.org/licenses/by-nc-sa/4.0/)

hidrograma estudiado e hidrograma simulados con datos de EMA (Figura 8). El modelo alimentado con datos de imágenes de satélite iba muy bien hasta que en un periodo de dos días disminuyó su ajuste, entre el 19 y 21 de agosto, lo que lo llevó a un NSE de 0.531. El modelo de EMA es casi perfecto en referente a valores de caudales, así como en su predicción y volúmenes.

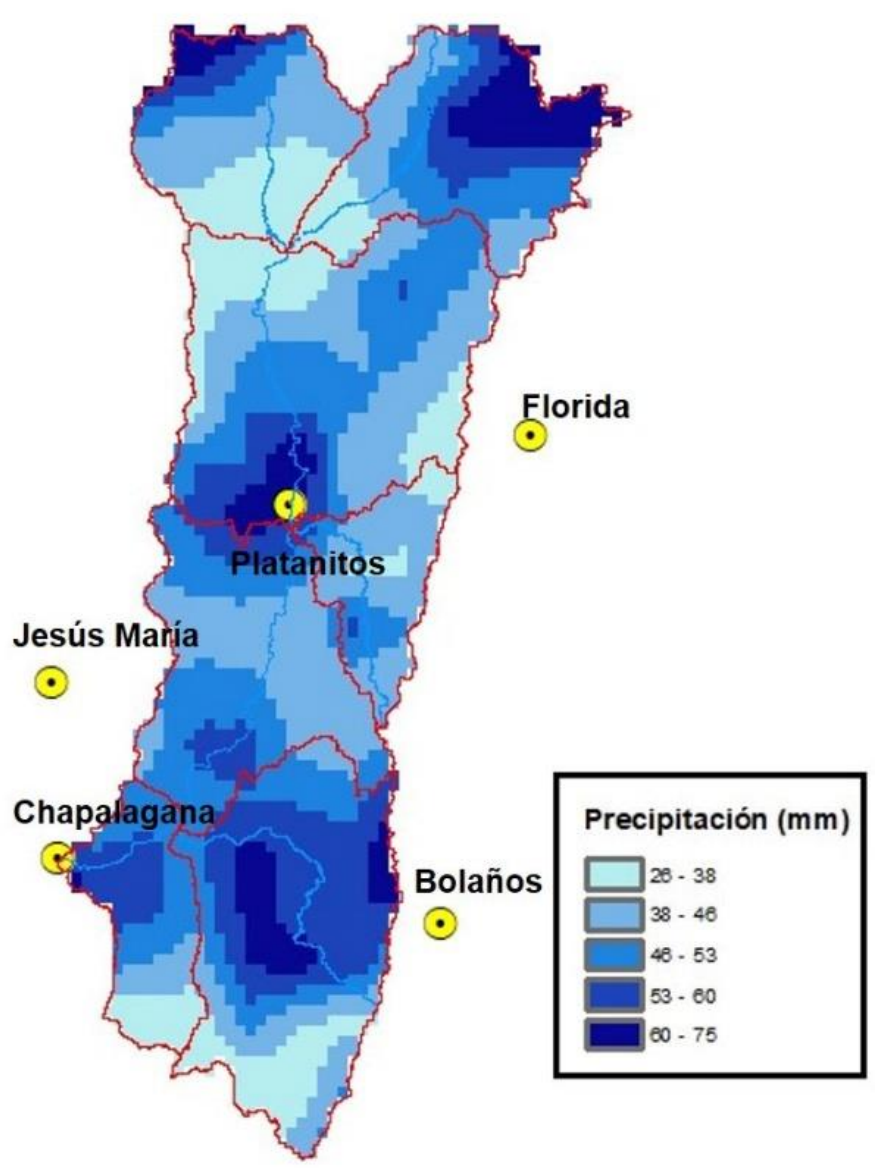

Figura 7. Precipitación acumulada con imágenes GPM-IMERG para el evento del 14 al 24 de agosto de 2017. 
Tecnología y

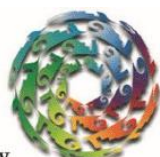

Ciencias $₫$ Agua
2020, Instituto Mexicano de Tecnología del Agua

Open Access bajo la licencia CC BY-NC-SA 4.0

(https://creativecommons.org/licenses/by-nc-sa/4.0/)

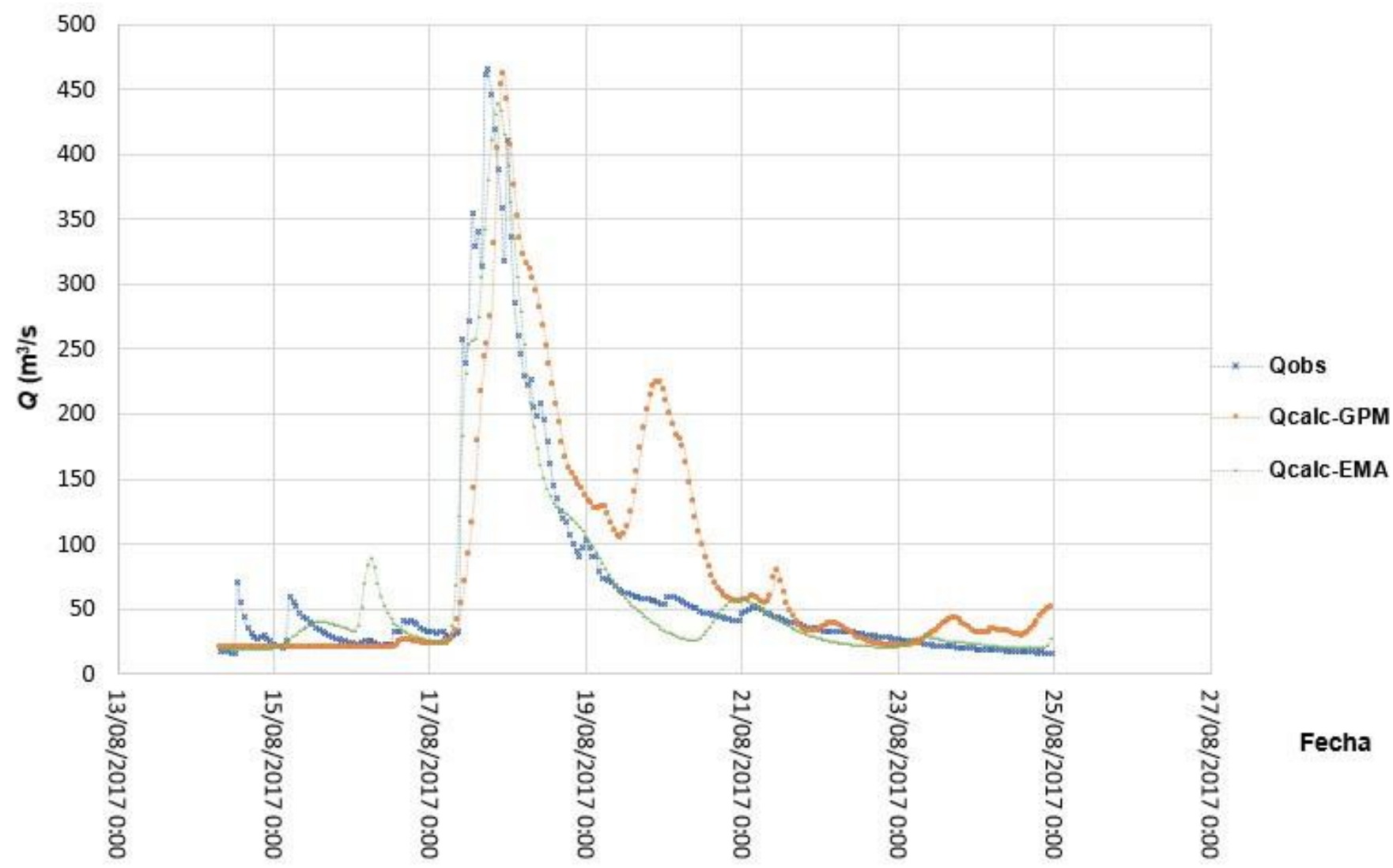

Figura 8. Caudales observados y simulados en la estación Chapalagana para el evento ocurrido del 14 al 24 de agosto de 2017.

La Figura 9 expone los datos procesados de lluvia a partir de las imágenes de satélite para el evento del $1^{\circ}$ al 16 de septiembre de 2017; la Figura 10 presenta las corridas del modelo tanto con datos de EMA como con datos de imágenes de satélite. Se observa, en lo referente a caudales máximos, que el modelo alimentado con datos de EMA presenta los mejores resultados con NSE $=0.567$. El modelo alimentado 
2020, Instituto Mexicano de Tecnología del Agua

Open Access bajo la licencia CC BY-NC-SA 4.0

(https://creativecommons.org/licenses/by-nc-sa/4.0/)

con datos de imágenes presenta un NSE de 0.530. Cabe mencionar que aunque el modelo de EMA medido con NSE y RSME es ligeramente superior, se observa que en el modelo alimentado con dato de Iluvia de las imágenes, el error en estimar el caudal máximo es de $17 \%$; mientras que el error al estimar dicho caudal con modelo de EMA es de alrededor de $50 \%$. En lo que atañe a volúmenes, también el modelo alimentado con EMA presenta mejores resultados.

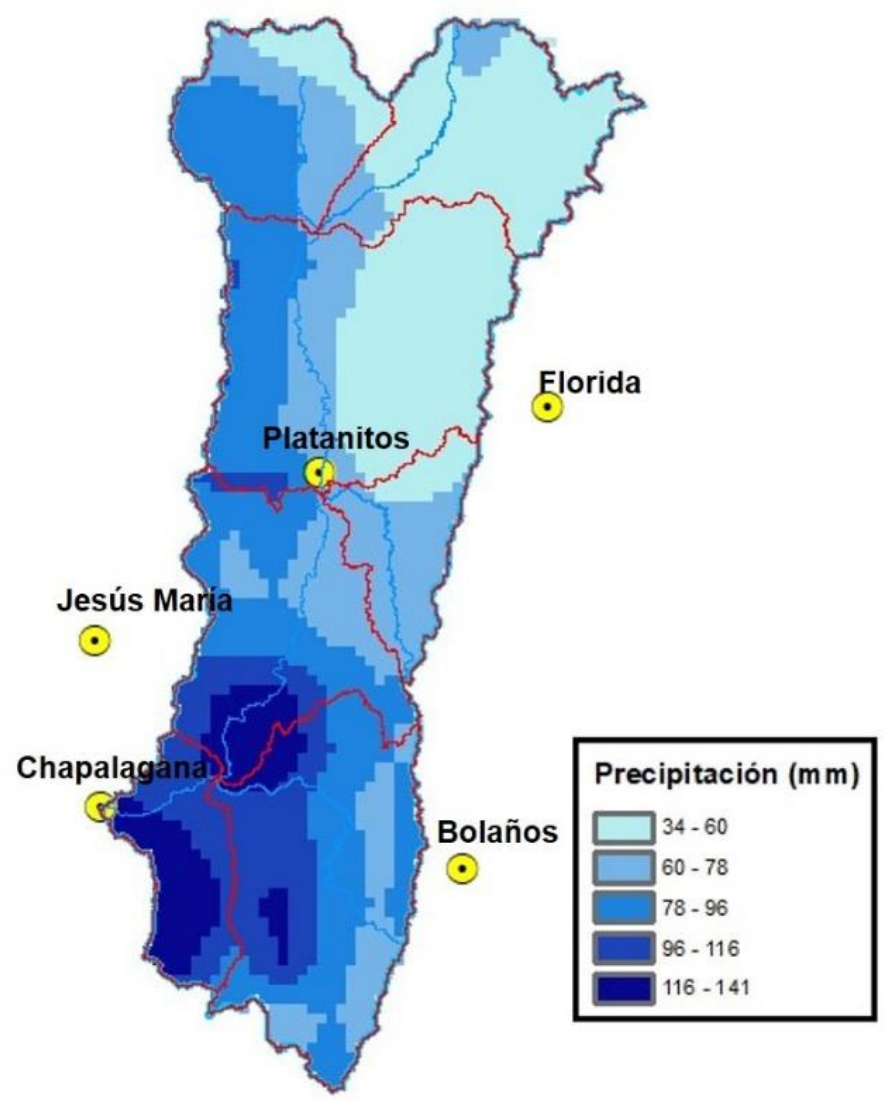

Figura 9. Precipitación acumulada con imágenes GPM-IMERG para el evento del $1^{\circ}$ al 16 de septiembre de 2017. 
Tecnología y

Ciencias $₫$ Agua
2020, Instituto Mexicano de Tecnología del Agua

Open Access bajo la licencia CC BY-NC-SA 4.0

(https://creativecommons.org/licenses/by-nc-sa/4.0/)

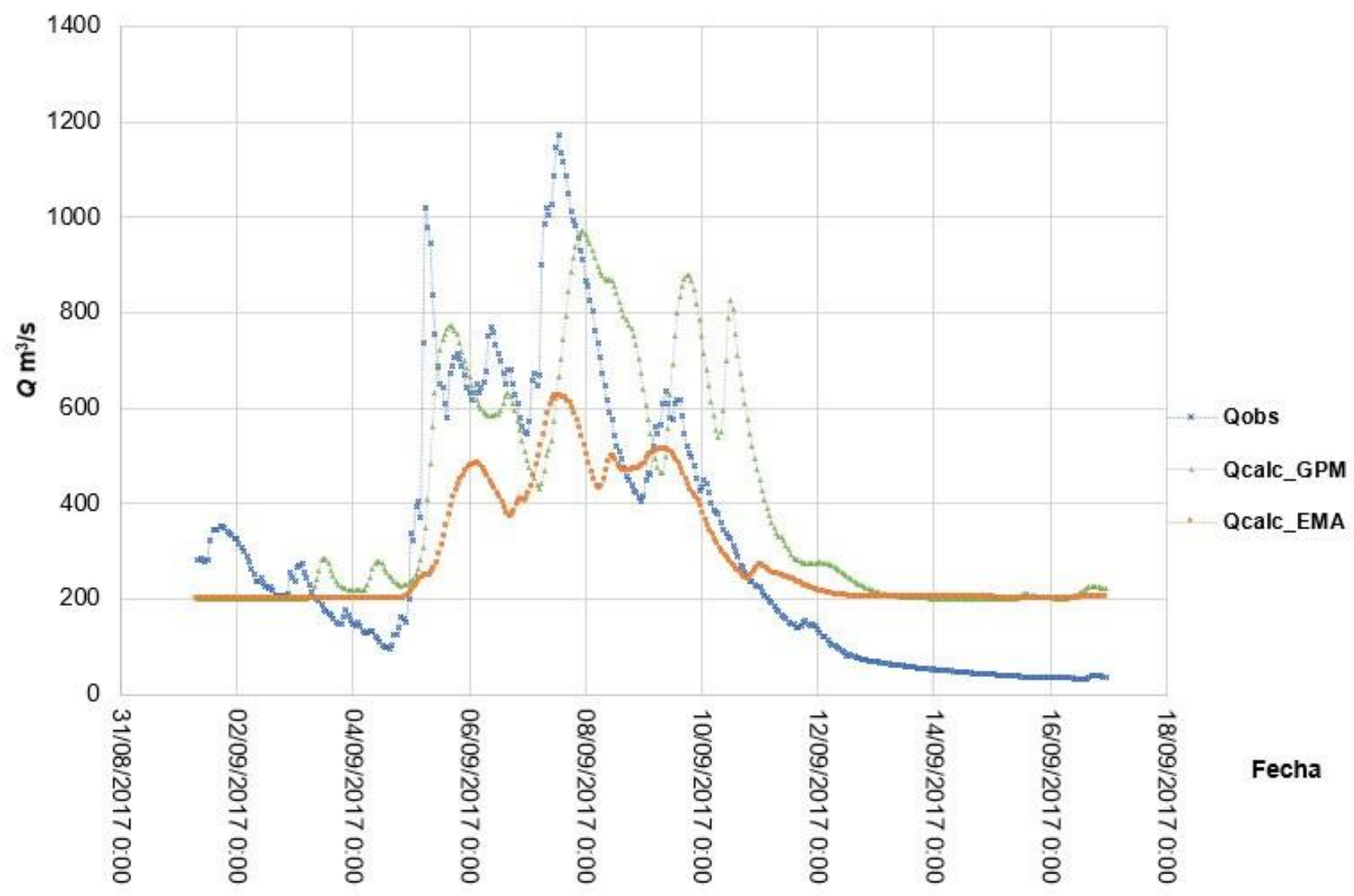

Figura 10. Caudales observados y simulados en la estación Chapalagana para el evento del $1^{\circ}$ al 16 de septiembre de 2017.

Si este trabajo se compara con otros previos, hechos en México, quizá sería con aquellos que emplean el modelo hidrológico alimentado con datos de lluvia de radar. En ellos, su tamaño de cuenca va de 35 a 3 242 km² (Magaña-Hernández et al., 2013; Méndez-Antonio et al., 2014); en este trabajo se refirió a una cuenca de alrededor de 12000 
2020, Instituto Mexicano de Tecnología del Agua

Open Access bajo la licencia CC BY-NC-SA 4.0

(https://creativecommons.org/licenses/by-nc-sa/4.0/)

$\mathrm{km}^{2}$, lo que dificulta más la instrumentación y representación de la distribución espacial de la lluvia.

Existen dos trabajos relativamente recientes sobre modelos hidrológicos con imágenes de satélite (Zubieta et al., 2017; Zubieta, Laqui, \& Lavado, 2018). Ambos usan imágenes de satélite para la Iluvia, pero uno es a escala de tiempo diaria y el otro es mensual. En este trabajo, la escala es horaria.

\section{Discusión}

Se observó mayor eficiencia de Nash-Sutcliffe en cada uno de los eventos simulados con modelos agregados usando el hidrograma unitario de Clark, al cual se le suministró la precipitación de cinco estaciones distribuidas en una superficie de $12075 \mathrm{~km}^{2}$, que tiene la cuenca del río Huaynamota, a pesar de que no representa una distribución espacial uniforme de la precipitación.

Lo anterior pudiera explicarse por dos razones: (1) la velocidad del flujo se consideró constante entre cada una de las celdas, afectando los parámetros de tiempo de concentración y el coeficiente de almacenamiento; el tamaño de celda para cada una de las mallas 
2020, Instituto Mexicano de Tecnología del Agua

Open Access bajo la licencia CC BY-NC-SA 4.0

(https://creativecommons.org/licenses/by-nc-sa/4.0/)

utilizadas en el desarrollo del trabajo fue de $2 \mathrm{~km} \times 2 \mathrm{~km}$; (2) en definitiva, los datos medidos en tierra son más confiables que los de las imágenes. Sin embargo, las imágenes de satélite GPM-IMERG de la NASA son una opción que no tiene información meteorológica de tierra, con la suficiente distribución espacial y temporal (horaria).

\section{Conclusiones}

Los datos de lluvia registrados por las estaciones meteorológicas automáticas (EMA), comparados a los de las imágenes de satélite GPMIMERG, representaron mejor el proceso lluvia-escurrimiento.

Considerando que la precipitación es el insumo principal en la modelación hidrológica, el uso de esta nueva generación de imágenes es de gran interés en estudios hidrológicos, pero habría que considerar en futuras investigaciones la calibración de las imágenes a partir de información de precipitación de estaciones ubicadas en el territorio nacional.

Se concluye, a partir de los resultados de la modelación hidrológica con datos de Iluvia estimados de imágenes y comparados al modelo con datos de lluvia de EMA, que las imágenes son una buena 
2020, Instituto Mexicano de Tecnología del Agua

Open Access bajo la licencia CC BY-NC-SA 4.0

(https://creativecommons.org/licenses/by-nc-sa/4.0/)

opción para la modelación hidrológica y aplicable a lugares en donde la información meteorológica medida en tierra es deficiente.

\section{Agradecimientos}

A la Comisión Federal de Electricidad, por permitirnos acceso a su base de datos hidrometeorológica, a través del sitio web administrado por el Instituto Nacional de Electricidad y Energías Limpias.

\section{Referencias}

Bedient, P. B., Huber, W. C., \& Vieux, B. E. (2013). Hydrology and floodplain analysis ( $5^{\text {th }}$ ed.). New York, USA: Pearson.

Chow, V. T., Maidment, D. R., \& Mays, L. W. (1988). Applied hydrology. New York, USA: McGraw-Hill.

CFE, Comisión Federal de Electricidad. (2018). Sistema de Monitoreo de Cuencas de CFE. Recuperado de https://h06814.iie.org.mx/cuencas/logon.aspx?ReturnUrl=\%2Fcue ncas\%2Fdefault.aspx

Domínguez, M. R., Esquivel, G. G., Méndez, A. B., Mendoza, R. A., Arganis, J. M. L., \& Carrioza, E. E. (2008). Manual del modelo para pronóstico de escurrimiento. Ciudad de Mexico, México: Instituto de Ingeniería, Universidad Nacional Autónoma de México. Recuperado de https://doi.org/10.13140/RG.2.1.4687.5287

Huffman, G. J., Bolvin, D. T., \& Nelkin, E. J. (2017). Integrated multi- 
2020, Instituto Mexicano de Tecnología del Agua

Open Access bajo la licencia CC BY-NC-SA 4.0 (https://creativecommons.org/licenses/by-nc-sa/4.0/)

satellite retrievals for GPM (IMERG) Technical documentation. Purdue, USA: National Aeronautics and Space Administration.

INEGI, Instituto Nacional de Estadística y Geografía. (2017a). Conjunto de datos vectoriales de uso de suelo y vegetación. Serie $V$. Recuperado de https://www.inegi.org.mx/temas/usosuelo/

INEGI, Instituto Nacional de Estadística y Geografía. (2017b). Conjunto de datos vectoriales edafológico. Serie II. Recuperado de https://www.inegi.org.mx/temas/edafologia/

INEGI, Instituto Nacional de Estadística y Geografía. (2017c). Continuo de elevaciones mexicano 3.0 (CEM 3.0). Recuperado de https://www.inegi.org.mx/app/geo2/elevacionesmex/index.jsp

Ioannidou, M. P., Kalogiros, J. A., \& Stavrakis, A. K. (2016). Comparison of the TRMM precipitation radar rainfall estimation with groundbased disdrometer and radar measurements in South Greece. Atmospheric Research, 181, 172-185. Recuperado de https://doi.org/10.1016/j.atmosres.2016.06.023

Kull, D. W., \& Feldman, A. D. (1998). Evolution of Clark's unit graph method to spatially distributed runoff. Journal of Hydrologic Engineering, 3(1), 9-19. Recuperado de https://doi.org/10.1061/(ASCE)1084-0699(1998)3:1(9)

Magaña-Hernández, F., Ba, K. M., \& Guerra-Cobián, V. H. (2013). Estimación del hidrograma de crecientes con modelacion determinística y precipitación derivada de radar. Agrociencia, 47(8), 739-752. 
2020, Instituto Mexicano de Tecnología del Agua

Open Access bajo la licencia CC BY-NC-SA 4.0 (https://creativecommons.org/licenses/by-nc-sa/4.0/)

McCuen, R. H., Wong, S. L., \& Rawls, W. J. (1984). Estimating urban time of concentration. Journal of Hydraulic Engineering, 110(7), 887-1002. Recuperado de https://doi.org/10.1061/(ASCE)07339429(1984)110:7(887)

Méndez-Antonio, B., Caetano, E., Soto-Cortés, G., Rivera-Trejo, F. G., Carvajal Rodríguez, R. A., \& Watts, C. (2013). Weather radar data and distributed hydrological modelling: An application for Mexico Valley. Open Journal of Modern Hydrology, 3(2), 79-88. Recuperado de https://doi.org/10.4236/ojmh.2013.32011

Méndez, A. B., Soto-Cortés, G., Rivera-Trejo, F., \& Caetano, E. (2014). Modelación hidrológica distribuida apoyada en radares meteorológicos. Tecnología y ciencias del agua, 5(1), 83-101.

Moriasi, D. N., Arnold, J. G., Van Liew, M. W., Bingner, R. L., Harmel, R. D. \& Veith T. L. (2007). Model evaluation guidelines for systematic quantification of accuracy in watershed simulations. American Society of Agricultural and Biological Engineers, 50(3), 885-900. Recuperado de https://doi.org/10.13031/2013.23153

Nash, J. E., \& Sutcliffe, J. V. (1970). River forecasting trough conceptual models. Part 1 - A discussion of principles. Journal of Hydrology, 10(3), 282-290. Recuperado de https://www.sciencedirect.com/science/article/abs/pii/002216947 0902556?via\%3Dihub

Olivera, F., \& Maidment, D. (1999). Geographic information systems (GIS)-based spatially dustributed model for runoff routing. Water 
2020, Instituto Mexicano de Tecnología del Agua

Open Access bajo la licencia CC BY-NC-SA 4.0

(https://creativecommons.org/licenses/by-nc-sa/4.0/)

Resources Research, 35(4), 1155-1164. Recuperado de https://www.researchgate.net/publication/228582442_Geographic _Information_Systems_GIS-

Based_Spatially_Distributed_Model_for_Runoff_Routing

Ponce, V. M., \& Hawkins, R. H. (1996). Runoff curve number: Has it reached maturity? Journal of Hydrologic Engineering, 1(1), 11-19. Recuperado de https://doi.org/10.1061/(ASCE)10840699(1996)1:1(11)

Sithara, J. (2015). GIS based Runoff estimation using NRCS method and time-area method. Scientific \& Engineering Research, 5(7), 306312.

USACE, United States Army Corps of Engineers. (1982). HEC-1 Training document No.15. California, USA: United States Army Corps of Engineers.

USACE, United States Army Corps of Engineers. (2000). Hydrologic Modeling System-HEC-HMS: Technical Reference Manual. Washington, DC, USA: United States Army Corps of Engineers.

USACE, United States Army Corps of Engineers. (2013). HEC-GeoHMS geospatial hydrologic modelling extension: user's manual version 4.2. User's manual-version 10.1. Recuperado de http://www.hec.usace.army.mil/software/hec-geohms/

USACE, United States Army Corps of Engineers. (2015). HEC-HMS user's manual version 4.1. Recuperado de http://www.hec.usace.army.mil/software/hec-hms/ 
2020, Instituto Mexicano de Tecnología del Agua

Open Access bajo la licencia CC BY-NC-SA 4.0

(https://creativecommons.org/licenses/by-nc-sa/4.0/)

USACE, United States Army Corps of Engineers. (2016). Workshop: Application of HEC-HMS using gridded precipitation in watersheds outside of the United States. Recuperado de https://www.hec.usace.army.mil/training/CourseMaterials/Mongoli a_Workshop/Workshop_Mongolia.pdf

Vargas-Castañeda, G., Ibáñez-Castillo, L. A., \& ArteagaRamírez, R. (2015). Development, classification and trends in rainfall-runoff modeling. Ingeniería

Agrícola

Biosistemas, 7(1), 5-21.

Recuperado

de http://dx.doi.org/10.5154/r.inagbi.2015.03.002

Vieux, B. (2004). Distributed hydrologic modeling using GIS. Water Science and Technology Library. Book 48 (2 ${ }^{\text {nd }}$ ed.). New York, USA: Springer.

Zubieta, R., Getirana, A., Espinoza, J. C., Lavado-Casimiro, W., \& Aragon, L. (2017). Hydrological modeling of the PeruvianEcuadorian Amazon Basin using GPM-IMERG satellite-based precipitation dataset. Hydrology and Earth System Sciences, 21(7), 3543-3555. Recuperado de https://doi.org/10.5194/hess21-3543-2017

Zubieta, R., Laqui, W., \& Lavado, W. (2018). Modelación hidrológica de la cuenca del río Ilave a partir de datos de precipitación observada y de satélite, periodo 2011-2015, Puno, Perú. Tecnología y ciencias del agua, 9(5), 85-105. Recuperado de https://doi.org/10.24850/j-tyca-2018-05-04 